\title{
3 Research Suare \\ Hot Temperature OGTT Induces Higher Insulin and GLP-1 Response Than Cold OGTT
}

\author{
Yun Hu \\ Nanjing Medical University \\ Peng Zhang \\ Nanjing Medical University \\ Bo Ding \\ Nanjing Medical University \\ Xin Cao \\ Nanjing Medical University \\ Yi Zhong \\ Nanjing Medical University \\ Yi-Xuan Sun \\ Nanjing Medical University \\ Kok-Onn Lee \\ National University Hospital \\ Jian-Hua Ma ( $\triangle$ majianhua196503@126.com ) \\ Nanjing Medical University
}

\section{Research Article}

Keywords: food temperature, glucagon like peptide-1, blood glucose, type 2 diabetes

Posted Date: September 7th, 2021

DOI: https://doi.org/10.21203/rs.3.rs-860351/v1

License: (c) (i) This work is licensed under a Creative Commons Attribution 4.0 International License.

Read Full License 


\section{Abstract}

Food temperature may be important in diabetes. Newly diagnosed treatment-naïve type 2 diabetes patients $(\mathrm{T} 2 \mathrm{DM}, 22)$ and normal controls $(19)$ were randomly assigned to either hot $\left(50^{\circ} \mathrm{C}\right)$ or cold $\left(8^{\circ} \mathrm{C}\right)$ oral glucose tolerance test (OGTT) on day 1 , and OGTT at the other temperature on the next day. Measurements were made on venous blood obtained at $0,5,10,30,60$, and 120 min. Compared to cold OGTT, blood glucose was significantly higher with hot OGTT in both groups. However, insulin and glucagon-like peptide-1 (GLP-1) levels were significantly higher in hot OGTT in normal subjects only. The glucose-dependent insulinotropic peptide (GIP) and cortisol responses did not differ with temperature in both groups. After the OGTT, subjects took corresponding, either hot $\left(>42^{\circ} \mathrm{C}\right)$ or cool (room temperature) meals and water, that entire day, followed by identical food at the other temperature the next day. Continuous glucose monitoring showed that normal subjects had significantly higher 24-hour mean glucose (MBG), and standard deviation of MBG with hot meals, T2DM patients had higher MBG only. Our study showed that blood glucose, insulin, and GLP-1 responses to different food temperatures may be deficient in newly diagnosed T2DM.

\section{Introduction}

While the timing ${ }^{1}$ and frequency of meals ${ }^{2,3}$ have been noted as important factors for the prevalence of diabetes and blood glucose control, food temperature has not been seen generally as important in type 2 diabetes mellitus (T2DM). Recently, ambient food temperature has attracted some attention in the understanding of diabetes in Asian populations - where food temperature had some effects on the glycemic response to rice ${ }^{4}$ and potatoes ${ }^{5}$. Early phase insulin release in animal studies (anesthetized rats) ${ }^{6}$ were also reported to be affected by food temperature. However, as far as we know, there have not been comparisons of the endocrine effects of ambient glucose or food temperature on the response to OGTT, or to normal daily meals.

The ambient temperature of ingested food has been shown to affect gastric emptying ${ }^{7-9}$, but as far as we know, the subsequent effects on blood glucose, and the responses in insulin and other gut-related hormones, have not been studied. There are large differences in ambient food and drink temperatures between different cuisines in most countries. Cold drinks are common in fast-food restaurants, but hot soups are the norm in many meals in much of East Asia. In recent years, there has been a large increase in many parts of East Asia, especially in China, of 'hot pot' food, served often at temperatures above $50^{\circ} \mathrm{C}$.

In the present study, we investigated the blood glucose, and glucose responsive hormones to a standard oral glucose tolerance test (OGTT) with hot or cold temperature glucose in normal subjects, and in newly diagnosed untreated patients with type 2 diabetes (T2DM). We further performed continuous glucose monitoring (CGM) in these two groups on the two different days, to compare the glucose profiles of hot versus cold food and water throughout the day.

\section{Materials And Methods}




\section{Study Population}

We enrolled 19 normal subjects and 22 newly diagnosed patients with T2DM at the Nanjing First Hospital between June 2017 and October 2019. The normal subjects were healthy and had no known illness. The patients with T2DM were all newly diagnosed through health screening and had mild diabetes that did not require urgent treatment. The inclusion criteria for the two groups were as follows: 1 . normal participants: no previous history of diabetes or any other illness; fasting plasma glucose $<6.1 \mathrm{mmol} / \mathrm{L}$ and 2-h plasma glucose $<7.8 \mathrm{mmol} / \mathrm{L}$ after 75-g OGTTs (the diagnostic criteria of World Health Organization 1999); 2. newly diagnosed patients with T2DM (diagnostic criteria of World Health Organization); $\mathrm{HbA}_{1 \mathrm{c}}<86 \mathrm{mmol} / \mathrm{mol}$ (10.0\%). Both groups had BMI within $18.0 \sim 28.0 \mathrm{~kg} / \mathrm{m}^{2}$ and were aged 18 60 years. Participants with the following were also excluded: 1 . any history of hypoglycemic agent intake or were presently taking hypoglycemic agents; 2 . any abnormality in liver or kidney function on blood and urine investigations 3 . any history of systemic corticosteroid use in 3 months; 4 . any recent infections or acute medical events; 5 . pregnancy.

The study was reviewed and approved by the Institutional Ethics Committee of Nanjing First Hospital, Nanjing Medical University, and signed informed consent was obtained from all study participants. This trial was registered in ChiCTR (ChiCTR-00C-17011643, Registered 12 Jun 2017, http://www.chictr.org.cn/showproj.aspx?proj=19708). This study was carried out in accordance with the Helsinki Declaration, and all methods were carried out in accordance with relevant guidelines and regulations.

\section{OGTT with different temperature}

All experiments were conducted at a dedicated facility at the hospital with an ambient temperature of $22^{\circ} \mathrm{C}$. After an overnight fast (>10 hours), half the participants were assigned randomly to either a hot or cold OGTT at 8:00 am, and instructed to take the corresponding hot or cold food throughout the day. The participants then all took the alternative temperature OGTT and food the next day.

Hot and cold glucose solutions were prepared as follows: $75 \mathrm{~g}$ anhydrous glucose was dissolved in 300 $\mathrm{ml}$ water. Cold glucose solution was cooled in a refrigerator $\left(4^{\circ} \mathrm{C}\right)$, while the hot glucose solution was heated in a water bath $\left(55^{\circ} \mathrm{C}\right)$. The final temperature of glucose solution was measured just before oral administration to ensure the temperature of $6-8{ }^{\circ} \mathrm{C}$ for the cold OGTT and about $50{ }^{\circ} \mathrm{C}$ for the hot OGTT. Venous blood was sampled at $0,5,10,30,60$, and 120 min during OGTT. The OGTT was repeated at the opposite temperature the next morning. After the hot OGTT, participants were given hot food for lunch and dinner for the rest of the day and instructed to avoid cool food or water. Similarly, after the cold OGTT, the participants took cold food and water. The food on both days was identical in composition and total energy content to avoid differences in 'chili' (capsaicin) related and other gustatory differences. The 'hot' foods included hot soup, noodles, rice, vegetables, and meat at temperatures of $45-55^{\circ} \mathrm{C}$. Cold food was at room temperature of $20-24{ }^{\circ} \mathrm{C}$. None of the subjects reported any difficulty with these food temperatures. All meals were consumed within 30 minutes. 


\section{Clinical and Laboratory assessments}

Height, weight, age, and medical history were collected at the first visit. Body mass index (BMI) was calculated as weight divided by the square of height $\left(\mathrm{kg} / \mathrm{m}^{2}\right)$. Plasma blood glucose levels were measured using the glucose oxidase method with an auto-analyzer (Modular E170, Roche, Mannheim, Germany). $\mathrm{HbA}_{1 \mathrm{c}}$ was measured by high-performance liquid chromatography assay (Bio-Rad Laboratories, Inc., CA, USA). Insulin levels were measured by chemiluminescent immunometric assay using the Modular Analytics E170 (Roche ${ }^{\circledR}$ Diagnostics $\mathrm{GmbH}$, Mannheim, Germany, reference range: 2.3 11.6 mU/L). Plasma cortisol was determined with quantitative radioimmunoassay (Beijing North Institute of Biological Technology, CN). Measurements of glucagon-like peptide-1 (GLP-1) and glucosedependent insulinotropic peptide (GIP) were made in blood collected in precooled specimen tubes with added protease and DPP-IV inhibitors, and by ELISA assays (USCN LIFE, CN; intra-assay precision: $\mathrm{CV}<10 \%$; inter-assay precision: $\mathrm{CV}<12 \%$ ).

\section{Continuous glucose monitoring}

All participants had CGM for 3 consecutive days during this study. A CGM (Medtronic Incorporated, Northridge, CA, USA) sensor was implanted in the anterior abdomen one day before the first OGTT. Participants were instructed in the use of the device and were asked to measure capillary blood glucose four times daily for calibration. Interstitial glucose was continuously measured every 5 minutes (min). The CGM sensor was removed 24 hours after the second OGTT. The participants were asked to maintain their activities without strenuous exercise during CGM for the three consecutive days. Patients with capillary blood glucose $\geq 20.0 \mathrm{mmol} / \mathrm{L}$ at any time point were removed from the study. The 24-hours mean glucose (MBG), standard deviation of MBG (SDBG), coefficient of variation (CV), 24-hours largest amplitude of glycemic excursion (LAGE), and time in range (TIR) were recorded and compared between the two temperatures in the two groups ${ }^{10,11}$.

\section{Statistical analysis}

All statistical analyses were performed using the SPSS 22.0 software (SPSS Science, Chicago, USA). All variables were tested for normal distribution of the data and were expressed as mean \pm SEM, or as median (IQR). Each of the variables: glucose, insulin, GLP-1, GIP, and cortisol were analyzed by ANOVA for repeated measurements to test for statistical significance of the differences between hot and cold OGTT. If there was statistical significance between the two temperatures $(p<0.05)$, this was followed with a Bonferroni test for specific time points. The paired t-test was used in the comparison of CGM data between cool and hot meals in the same subject. Differences between the groups were examined using the Student's unpaired t-test or Mann-Whitney U-test. All comparisons were 2-sided at a $5 \%$ significance level. A $p$ value $<0.05$ was considered statistically significant.

\section{Results}




\section{Subject characteristics}

A total of 19 normal subjects and 22 newly diagnosed untreated T2DM patients completed the study. There was no significant difference of gender or age between the two groups ( $p$ all >0.05). The T2DM patient had a higher BMl and $\mathrm{HbA}_{1 \mathrm{c}}$ compared to normal subjects (Table 1).

Table 1

Characteristics of subjects in different groups.

\begin{tabular}{|llll|}
\hline & Normal & T2DM & $p$ value \\
\hline $\mathrm{N}$ & 19 & 22 & - \\
\hline Gender (male\%) & $47.37 \%$ & $68.18 \%$ & 0.216 \\
\hline Age (year) & $38.95 \pm 2.55$ & $44.41 \pm 1.73$ & 0.077 \\
\hline BMI $\left(\mathrm{kg} / \mathrm{m}^{2}\right)$ & $22.33 \pm 0.59$ & $26.02 \pm 0.61$ & $<0.001$ \\
\hline HbA1c $(\%)$ & $5.28 \pm 0.08$ & $6.93 \pm 0.28$ & $<0.001$ \\
\hline T2DM, type 2 diabetes; N, number; BMI, body mass index; HbA1c, glycated hemoglobin \\
\hline
\end{tabular}

\section{Changes After Hot And Cold Ogtt}

Table 2 shows the mean $( \pm \mathrm{SE}$ ) values for each variable after hot versus cold OGTT after comparison with ANOVA for repeated measures. The mean blood glucose was significantly higher after a hot OGTT compared to a cold OGTT in both groups ( $p=0.002$ and 0.028 , respectively, Table 2, Fig. 1a, and Fig. 2a). Insulin and GLP-1 were also significantly higher after hot OGTT compared to cold OGTT, but only in normal subjects (both $p<0.05$ ), and not in the T2DM patients (both $p>0.05$, Table 2, Fig. 1b, c, and Fig. 2b, c). The differences between the hot and cold post-OGTT responses in cortisol (Fig. 1d and 2d) and GIP (data not shown) did not reach statistical significance in both groups. 
Table 2

Measurements after cold and hot OGTTs with ANOVA (repeated measures)

\begin{tabular}{|c|c|c|c|c|c|c|c|}
\hline & & $\begin{array}{l}\text { Cold } \\
\text { OGTT }\end{array}$ & $\begin{array}{l}\text { Hot } \\
\text { OGTT }\end{array}$ & $\begin{array}{l}p \\
\text { value }\end{array}$ & $\begin{array}{l}\text { Increment in } \\
\text { cold OGTT (\%) }\end{array}$ & $\begin{array}{l}\text { Increment in } \\
\text { hot OGTT (\%) }\end{array}$ & $\begin{array}{l}p \\
\text { value }\end{array}$ \\
\hline \multirow[t]{2}{*}{$\begin{array}{l}\text { Glucose } \\
(\mathrm{mmol} / \mathrm{L})\end{array}$} & Normal & $\begin{array}{l}6.33 \pm \\
0.15\end{array}$ & $\begin{array}{l}6.79 \pm \\
0.14\end{array}$ & 0.002 & $122.46 \pm 2.21$ & $129.17 \pm 2.53$ & 0.015 \\
\hline & T2DM & $\begin{array}{l}11.35 \pm \\
0.51\end{array}$ & $\begin{array}{l}11.88 \pm \\
0.56\end{array}$ & 0.028 & $151.42 \pm 2.24$ & $155.27 \pm 3.51$ & 0.104 \\
\hline \multirow[t]{2}{*}{$\begin{array}{l}\text { Insulin } \\
(\mathrm{mU} / \mathrm{L})\end{array}$} & Normal & $\begin{array}{l}40.34 \pm \\
3.00\end{array}$ & $\begin{array}{l}46.73 \pm \\
3.90\end{array}$ & 0.028 & $\begin{array}{l}784.07 \pm \\
228.61\end{array}$ & $621.54 \pm 65.79$ & 0.479 \\
\hline & T2DM & $\begin{array}{l}32.33 \pm \\
4.71\end{array}$ & $\begin{array}{l}34.81 \pm \\
6.03\end{array}$ & 0.317 & $359.37 \pm 34.89$ & $400.41 \pm 45.13$ & 0.175 \\
\hline \multirow[t]{2}{*}{$\begin{array}{l}\text { GLP-1 } \\
\text { (pmol/L) }\end{array}$} & Normal & $\begin{array}{l}16.99 \pm \\
1.34\end{array}$ & $\begin{array}{l}19.19 \pm \\
1.84\end{array}$ & 0.047 & $111.36 \pm 7.56$ & $130.20 \pm 5.86$ & 0.009 \\
\hline & T2DM & $\begin{array}{l}14.46 \pm \\
1.04\end{array}$ & $\begin{array}{l}15.40 \pm \\
0.89\end{array}$ & 0.219 & $115.11 \pm 5.59$ & $117.41 \pm 6.02$ & 0.783 \\
\hline \multirow[t]{2}{*}{$\begin{array}{l}\text { GIP } \\
(\mathrm{pmol} / \mathrm{L})\end{array}$} & Normal & $\begin{array}{l}72.05 \pm \\
6.77\end{array}$ & $\begin{array}{l}68.48 \pm \\
5.43\end{array}$ & 0.138 & $111.80 \pm 5.33$ & $116.71 \pm 8.71$ & 0.621 \\
\hline & T2DM & $\begin{array}{l}52.98 \pm \\
5.03\end{array}$ & $\begin{array}{l}50.74 \pm \\
5.04\end{array}$ & 0.327 & $113.38 \pm 4.55$ & $111.26 \pm 6.23$ & 0.731 \\
\hline \multirow[t]{2}{*}{$\begin{array}{l}\text { Cortisol } \\
\text { (nmol/L) }\end{array}$} & Normal & $\begin{array}{l}113.96 \\
\pm 4.78\end{array}$ & $\begin{array}{l}104.8 \pm \\
8.67\end{array}$ & 0.220 & $103.89 \pm 6.04$ & $94.47 \pm 4.40$ & 0.159 \\
\hline & T2DM & $\begin{array}{l}144.47 \\
\pm 9.19\end{array}$ & $\begin{array}{l}149.17 \\
\pm 12.70\end{array}$ & 0.619 & $105.76 \pm 544$ & $92.95 \pm 4.55$ & 0.087 \\
\hline
\end{tabular}

Further analysis of the differences in individual time points was made if the ANOVA for repeated measurements in each group was statistically significant. The blood glucose levels were higher in hot OGTT than in cold OGTT at 5, 10,30 and $120 \mathrm{~min}$ in the normal group, as well as at $5 \mathrm{~min}$ in the T2DM group ( $p$ all $<0.05$, Fig. 1a and Fig. 2a). Insulin levels were also higher in hot OGTT than in cold OGTT at the early time points of 5 and $10 \mathrm{~min}$ in the normal group ( $p=0.002$ and $p=0.027$, respectively, Fig. $1 \mathrm{~b}$ ). Statistically significant differences in GLP-1 between hot and cold OGTTs were found at 10 and 30 min in normal subjects ( $p=0.037$ and 0.023 , Fig. $1 c)$. These differences of insulin and GLP-1 between OGTTs were absent in patients with T2DM ( $p$ all >0.05, Fig. $2 b$ and $c)$.

We also expressed the changes in blood glucose, insulin, GLP-1, GIP, and cortisol levels as a percentage of the individual baseline level for each individual participant. The incremental blood glucose levels remained higher in hot OGTT than in cold OGTT, as well as the incremental GLP-1 levels in normal subjects ( $p=0.015$ and 0.009 , respectively, Table 2). Percentage change of blood glucose showed a 
significant elevation in hot OGTT compared with cold OGTT at 5 and 120 min in the normal group, as well as GLP-1 at 10 to 30 min ( $p$ all $<0.05$, Fig. $3 a$ and e). However, these differences were absent in patients with T2DM (both $p>0.05$, Fig. 3b and f). The percentage changes in insulin were similar in cold and hot OGTTs in both groups ( $p$ all $>0.05$, Fig. $3 c, d$ ).

\section{Factors affecting the difference of GLP-1 response between cold and hot OGTTs}

We further investigated factors which may influence the glucose and GLP-1 response between cold and hot OGTTs ( $\triangle \mathrm{i}$ AUC glucose/GLP-1 = iAUC for glucose/GLP-1 in hot OGTT minus that in cold OGTT). We performed a stepwise linear regression analysis for each group separately, and for all 41 participants, with age, sex, $\mathrm{BMI}, \mathrm{HbA}_{1 \mathrm{c}}$, and difference of temperature between cold and hot OGTTs as independent variables. However, none of these other factors had a statistically significant correlation with $\triangle \mathrm{i} A U C$ glucose or GLP-1.

\section{Glycemic Variation During Hot And Cold Food Intake Days}

The data of CGM also showed a statistically significant higher MBG in hot OGTT plus hot food and water, compared with cold OGTT with room temperature food and water throughout the day in both normal and diabetes groups ( $p=0.021$ and 0.022 , respectively, Table 3 ). The SDBG in the hot food intake day was significantly higher than in cold food intake day only in the normal group $(p=0.043)$, and was absent in the diabetes group ( $p=0.393$, Table 3$)$. However, there was no statistically significant difference of CV, TIR, and LAGE between the hot and cold food intake days in both groups ( $p$ all $>0.05$, Table 3 ).

Table 3

Glycemic variability in CGM during hot and cold food intake days

\begin{tabular}{|c|c|c|c|c|c|c|}
\hline & \multicolumn{3}{|l|}{ Normal } & \multicolumn{3}{|c|}{ Type 2 diabetes } \\
\hline & Cold & Hot & $\begin{array}{l}p \\
\text { value }\end{array}$ & Cold & Hot & $p$ value \\
\hline MBG (mmol/L) & $5.84 \pm 0.11$ & $6.11 \pm 0.13$ & 0.021 & $8.46 \pm 0.38$ & $8.88 \pm 0.39$ & 0.022 \\
\hline $\begin{array}{l}\text { SDBG } \\
(\mathrm{mmol} / \mathrm{L})\end{array}$ & $0.48 \pm 0.05$ & $0.59 \pm 0.06$ & 0.043 & $1.87 \pm 0.22$ & $1.98 \pm 0.20$ & 0.393 \\
\hline CV (\%) & $8.11 \pm 0.77$ & $9.45 \pm 0.92$ & 0.106 & $\begin{array}{l}21.59 \pm \\
2.12\end{array}$ & $\begin{array}{l}21.66 \pm \\
1.87\end{array}$ & 0.962 \\
\hline TIR (\%) & $100(100,100)$ & $100(100,100)$ & 0.180 & $\begin{array}{l}78.23 \pm \\
4.87\end{array}$ & $\begin{array}{l}74.57 \pm \\
5.39\end{array}$ & 0.211 \\
\hline LAGE (mmol/L) & $2.43 \pm 0.29$ & $2.75 \pm 0.27$ & 0.063 & $8.40 \pm 0.87$ & $8.59 \pm 0.79$ & 0.849 \\
\hline
\end{tabular}




\section{Discussion}

We have demonstrated for the first time that hot food may give small but statistically significant higher post-OGTT blood glucose levels compared to cold food in both normal subjects and in untreated newly diagnosed T2DM patients. We have also shown for the first time that insulin and GLP-1 levels increased significantly more with a hot OGTT in normal subjects, and this effect is lost or deficient in newly diagnosed patients with T2DM.

The differences in glucose levels were small, but statistically significant and consistently demonstrated in the OGTT and the 24 hour CGM. These small differences are unlikely to make significant differences in the diagnosis of diabetes using the OGTT, but does suggest the use of a fasting glucose level as a more consistent and reliable method of diagnosis of diabetes as it would be unaffected by temperature differences. Interestingly, Booth GL et al. showed that each $10^{\circ} \mathrm{C}$ increase in mean 30-day temperature was associated with 1.06 times higher odds of gestational diabetes mellitus ${ }^{12}$.

The difference in GLP-1 after OGTT is interesting and is novel. If the temperature of ambient glucose and presumably, other foods, does affect the GLP-1 response, it may account for some of the discrepancy in the reports on GLP-1 in normal versus diabetes. When the GLP-1 agonists and DPP-4 inhibitors were first introduced, there were differences in the reports on whether patients with T2DM had lower GLP-1 levels compared to normal non-diabetic subjects ${ }^{13-15}$. As far as we can discern, all these studies did not have stringent controls on the ambient temperature of the ingested glucose or meals. Our present novel finding suggests that many of these studies may need to be controlled for the ambient temperature of ingestion.

Both glucotoxicity and hyperinsulinemia are known risk factors for type 2 diabetes and obesity ${ }^{16-18}$. Our study has some interesting possible implications, even though these remain speculative at this stage. In countries where fast food is commonly eaten, cold sugary beverages may raise the blood glucose less that hot sugary beverages, like hot tea or coffee! (Although of course, the advice should be to avoid the use of refined sugar in all drinks! ${ }^{19-22}$ ). In China and many other countries at a similar stage of economic development, with the increase in GDP, a higher consumption of sugar-sweetened beverages has become more common ${ }^{23,24}$. Intake of sugar-sweetened beverages was estimated to be responsible for 0.5 million diabetes new cases in $2011^{24}$. Soft drinks are usually consumed at cold temperatures in the summer, while sweetened-milk tea/coffee are usually consumed hot throughout the year. Our study may suggest the possibility that it may be preferable to choose sweet drinks that are cold, although this would need much further study!

The physiological mechanisms of hot OGTT leading to higher blood glucose are unclear. One reason may be that gastric emptying with cold drinks may be significantly slower than with hot drinks ${ }^{7,25}$. Charles $\mathrm{L}$ et al. found that after an OGTT, glucose and insulin were elevated in a hot environment $\left(43^{\circ} \mathrm{C}\right)$ compared with both the cold $\left(7.2^{\circ} \mathrm{C}\right)$ and the neutral $\left(22^{\circ} \mathrm{C}\right)$ environments ${ }^{26}$. They postulated that reduced plasma glucose in the cold was the result of an increase in glucose uptake by shivering muscles ${ }^{26,27}$. Cold exposure stimulates the sympathetic nervous system muscle glucose uptake ${ }^{28}$. Our findings were 
opposite to the study in rats from Shinozaki K et al. ${ }^{6}$, who found that blood glucose was lower within 15 min after warm glucose solution administration in rats. Their findings may be confounded by the presence of anesthesia, which may affect the nervous system and muscle shivering.

Others have shown that the ambient temperature of drinks and food may influence our perception of sweetness ${ }^{29-31}$. Green $B G$ et al. showed that cooling to $5-12^{\circ} \mathrm{C}$ can reduce the perceived sweetness intensity of a glucose solution, and decrease the response of TRPM5 in the sweet taste receptor (STR) transduction cascade ${ }^{31}$. The STR was also expressed in $L$ cells in the gastrointestinal tract ${ }^{32,33}$, and STR blocker lactisole attenuated GLP-1 secretion response to intragastric and intraduodenal glucose infusion in humans ${ }^{34}$. Therefore, the reduction of GLP-1 levels with a cold OGTT may be a direct or indirect effect of the lower stimulation on STR in the gut.

In summary, compared with cold glucose solution, hot glucose solution increased the blood glucose, blood insulin levels and GLP-1 levels. In patients with type 2 diabetes, GLP-1 response in hot OGTT was diminished for as yet unknown reasons.

\section{Declarations}

\section{Data availability}

Data are available upon reasonable request by contacting majianhua196503@126.com.

\section{Disclosures}

No conflicts of interest, financial or otherwise, are declared by the authors.

\section{Grants}

This study was supported by the National Key R\&D Program of China (No. 2018YFC1314103), the National Natural Science Foundation of China (No. 81870563).

\section{Authors' contributions}

$\mathrm{J}-\mathrm{HM}$ and $\mathrm{YH}$ are responsible for the conception and design of the study. $\mathrm{YH}$ carried out the statistical analysis and wrote the first draft of the manuscript. PZ, BD, XC, YZ, and Y-XS contributed to provide clinical samples and acquisition of data. K-OL approved the final version of the manuscript. J-HM contributed to obtain funding, and is the guarantor of this work. All authors revised the manuscript critically for important intellectual content.

\section{Acknowledgments}

We thank the participants for their cooperation, and members of Endocrinology department of Nanjing First hospital for their support. 


\section{References}

1. Jakubowicz, D. et al. Fasting until noon triggers increased postprandial hyperglycemia and impaired insulin response after lunch and dinner in individuals with type 2 diabetes: a randomized clinical trial., 38, 1820-1826 https://doi.org/10.2337/dc15-0761 (2015).

2. Robinson, E. et al. A systematic review and meta-analysis examining the effect of eating rate on energy intake and hunger. Am J Clin Nutr, 100, 123-151 https://doi.org/10.3945/ajcn.113.081745 (2014).

3. Hsieh, S. D., Muto, T., Murase, T., Tsuji, H. \& Arase, Y. Eating until feeling full and rapid eating both increase metabolic risk factors in Japanese men and women. Public Health Nutr, 14, 1266-1269 https://doi.org/10.1017/s1368980010003824 (2011).

4. Sonia, S., Witjaksono, F. \& Ridwan, R. Effect of cooling of cooked white rice on resistant starch content and glycemic response. Asia Pac J Clin Nutr, 24, 620-625 https://doi.org/10.6133/apjcn.2015.24.4.13 (2015).

5. Nadine Najjar, N. A. \& Hwalla, N. Glycemic and insulinemic responses to hot vs cooled potato in males with varied insulin sensitivity. Nutr. Res, 24, 993-1004 https://doi.org/org/10.1016/j.nutres.2004.09.002 (2004).

6. Shinozaki, K., Shimizu, Y., Shiina, T., Morita, H. \& Takewaki, T. Relationship between taste-induced physiological reflexes and temperature of sweet taste. Physiol Behav, 93, 1000-1004 https://doi.org/10.1016/j.physbeh.2008.01.006 (2008).

7. Sun, W. M., Houghton, L. A., Read, N. W., Grundy, D. G. \& Johnson, A. G. Effect of meal temperature on gastric emptying of liquids in man., 29, 302-305 https://doi.org/10.1136/gut.29.3.302 (1988).

8. Schirra, J. et al. Gastric emptying and release of incretin hormones after glucose ingestion in humans. J Clin Invest, 97, 92-103 https://doi.org/10.1172/JCl118411 (1996).

9. Horowitz, M., Edelbroek, M. A., Wishart, J. M. \& Straathof, J. W. Relationship between oral glucose tolerance and gastric emptying in normal healthy subjects., 36, 857-862 https://doi.org/10.1007/BF00400362 (1993).

10. Defronzo, R. A. et al. Prediction of diabetes based on baseline metabolic characteristics in individuals at high risk., 36, 3607-3612 (2013).

11. Lu, J. et al. Association of Time in Range, as Assessed by Continuous Glucose Monitoring, With Diabetic Retinopathy in Type 2 Diabetes., 41, 2370-2376 https://doi.org/10.2337/dc18-1131 (2018).

12. Booth, G. L. et al. Influence of environmental temperature on risk of gestational diabetes. CMAJ, 189, E682-E689 (2017).

13. Holst, J. J., Knop, F. K., Vilsboll, T., Krarup, T. \& Madsbad, S. Loss of incretin effect is a specific, important, and early characteristic of type 2 diabetes., 34 (Suppl 2), S251-257 https://doi.org/10.2337/dc11-s227 (2011).

14. Meier, J. J. \& Nauck, M. A. Is the diminished incretin effect in type 2 diabetes just an epi-phenomenon of impaired beta-cell function?, 59, 1117-1125 https://doi.org/10.2337/db09-1899 (2010). 
15. Toft-Nielsen, M. B. et al. Determinants of the impaired secretion of glucagon-like peptide- 1 in type 2 diabetic patients. J Clin Endocrinol Metab, 86, 3717-3723 https://doi.org/10.1210/jcem.86.8.7750 (2001).

16. Zimmet, P. Z., Collins, V. R., Dowse, G. K. \& Knight, L. T. Hyperinsulinaemia in youth is a predictor of type 2 (non-insulin-dependent) diabetes mellitus., 35, 534-541 (1992).

17. Ottosson-Laakso, E. et al. Glucose-Induced Changes in Gene Expression in Human Pancreatic Islets: Causes or Consequences of Chronic Hyperglycemia., 66, 3013-3028 https://doi.org/10.2337/db170311 (2017).

18. Stumvoll, M., Goldstein, B. J. \& van Haeften, T. W. Type 2 diabetes: principles of pathogenesis and therapy. Lancet (London, England), 365, 1333-1346 https://doi.org/10.1016/s0140-6736(05)61032$x(2005)$.

19. Fardet, A. \& Boirie, Y. Associations between food and beverage groups and major diet-related chronic diseases: an exhaustive review of pooled/meta-analyses and systematic reviews. Nutr Rev, 72, 741762 https://doi.org/10.1111/nure.12153 (2014).

20. Imamura, F. et al. Consumption of sugar sweetened beverages, artificially sweetened beverages, and fruit juice and incidence of type 2 diabetes: systematic review, meta-analysis, and estimation of population attributable fraction. Br J Sports Med, 50, 496-504 (2016).

21. O'Connor, L. et al. Prospective associations and population impact of sweet beverage intake and type 2 diabetes, and effects of substitutions with alternative beverages., 58, 1474-1483 (2015).

22. Basu, S., McKee, M., Galea, G. \& Stuckler, D. Relationship of soft drink consumption to global overweight, obesity, and diabetes: a cross-national analysis of 75 countries. Am J Public Health, 103, 2071-2077 (2013).

23. Zhang, N., Du, S. M. \& Ma, G. S. Current lifestyle factors that increase risk of T2DM in China. Eur J Clin Nutr, 71, 832-838 https://doi.org/10.1038/ejcn.2017.41 (2017).

24. Li, Y. et al. Time Trends of Dietary and Lifestyle Factors and Their Potential Impact on Diabetes Burden in China., 40, 1685-1694 (2017).

25. Sun, W. M. et al. Effect of drink temperature on antropyloroduodenal motility and gastric electrical activity in humans., 37, 329-334 https://doi.org/10.1136/gut.37.3.329 (1995).

26. Dumke, C. L. et al. The Effect of Environmental Temperature on Glucose and Insulin After an Oral Glucose Tolerance Test in Healthy Young Men. Wilderness Environ Med, 26, 335-342 https://doi.org/10.1016/j.wem.2015.03.002 (2015).

27. Vallerand, A. L., Frim, J. \& Kavanagh, M. F. Plasma glucose and insulin responses to oral and intravenous glucose in cold-exposed humans. J Appl Physiol (1985), 65, 2395-2399 https://doi.org/10.1152/jappl.1988.65.6.2395 (1988).

28. Blondin, D. P. et al. Contributions of white and brown adipose tissues and skeletal muscles to acute cold-induced metabolic responses in healthy men. The Journal of physiology, 593, 701-714 (2015).

29. Green, B. G. \& Frankmann, S. P. The effect of cooling on the perception of carbohydrate and intensive sweeteners. Physiol Behav, 43, 515-519 (1988). 
30. Calvino, A. M. Perception of sweetness: the effects of concentration and temperature. Physiol Behav, 36, 1021-1028 (1986).

31. Green, B. G. \& Nachtigal, D. Temperature Affects Human Sweet Taste via At Least Two Mechanisms. Chem Senses, 40, 391-399 (2015).

32. Feng, R. et al. Expression of sweet taste receptor and gut hormone secretion in modelled type 2 diabetes. Gen Comp Endocrinol, 252, 142-149 https://doi.org/10.1016/j.ygcen.2017.08.008 (2017).

33. Kokrashvili, Z., Mosinger, B. \& Margolskee, R. F. Taste signaling elements expressed in gut enteroendocrine cells regulate nutrient-responsive secretion of gut hormones. Am J Clin Nutr, 90, 822-825 (2009).

34. Gerspach, A. C., Steinert, R. E., Schonenberger, L., Graber-Maier, A. \& Beglinger, C. The role of the gut sweet taste receptor in regulating GLP-1, PYY, and CCK release in humans. American journal of physiology. Endocrinology and metabolism, 301, E317-325 https://doi.org/10.1152/ajpendo.00077.2011 (2011).

\section{Figures}

a

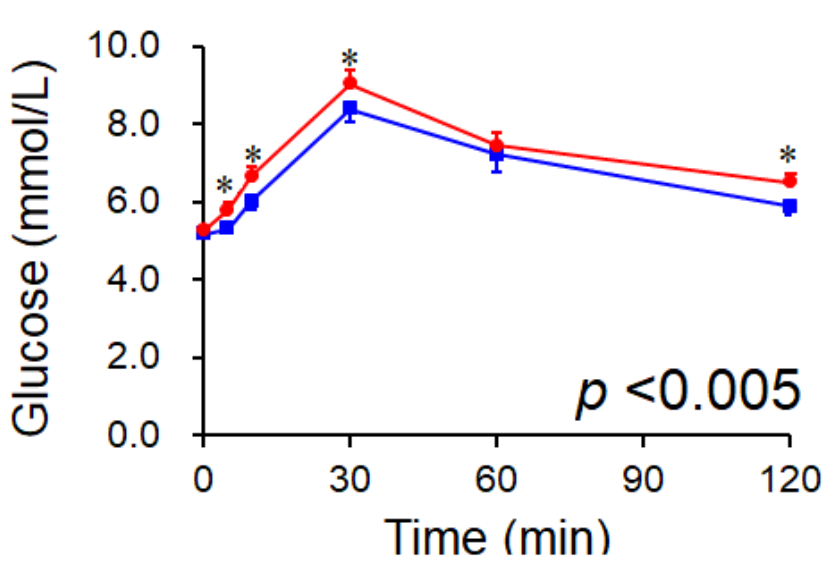

C

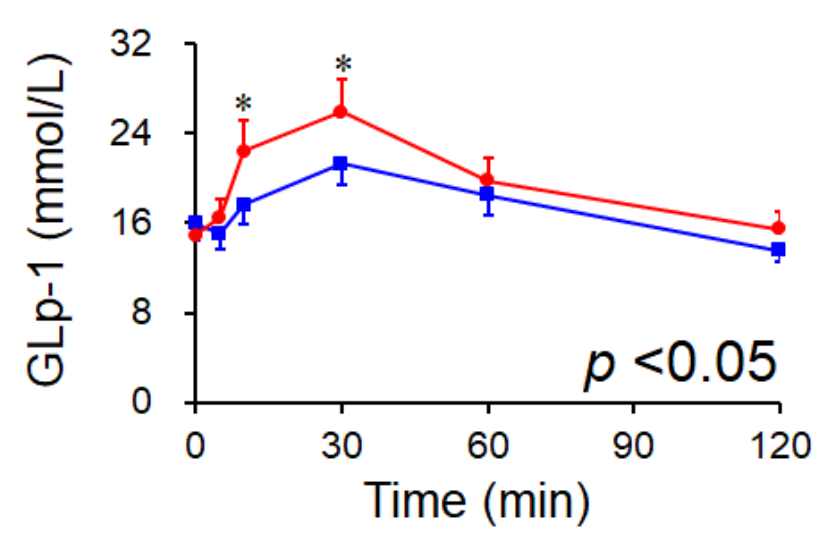

$b$

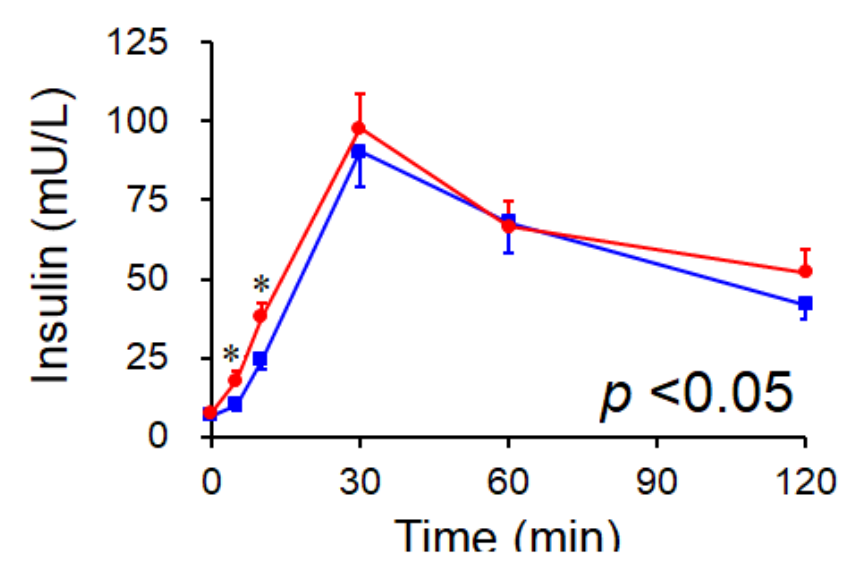

d

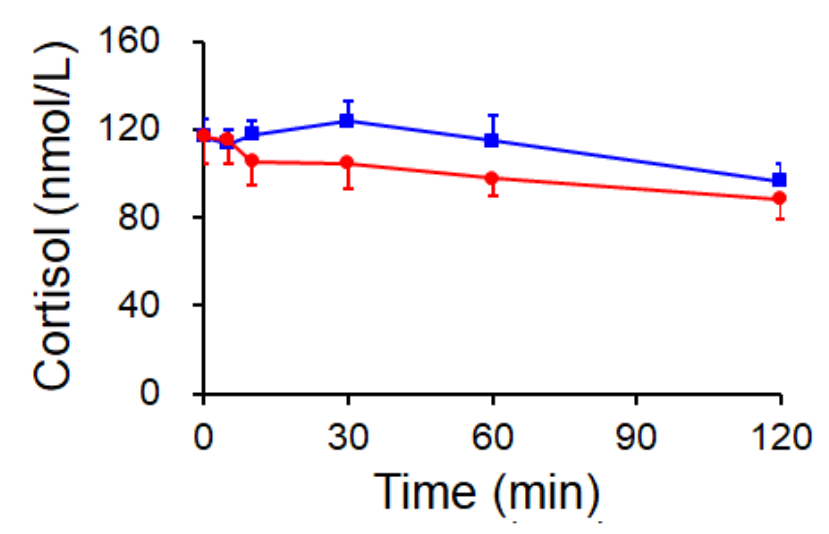




\section{Figure 1}

The blood glucose and glucose responsive hormone levels in cold and hot OGTTs in normal subjects. (a) blood glucose, (b) insulin, (c) GLP-1, and (d) cortisol levels in OGTTs in normal subjects ( $n=19)$. Data were analyzed with ANOVA for repeated measurements, and all ' $p$ ' values are from the ANOVA. If there was statistical significance between the two temperatures $(p<0.05)$, this was followed with a Bonferroni test for specific time points. Blue line=cold OGTT; red line=hot OGTT; *, $p<0.05$ in Bonferroni test. OGTT, oral glucose tolerance test; GLP-1, Glucagon-like peptide-1.

a

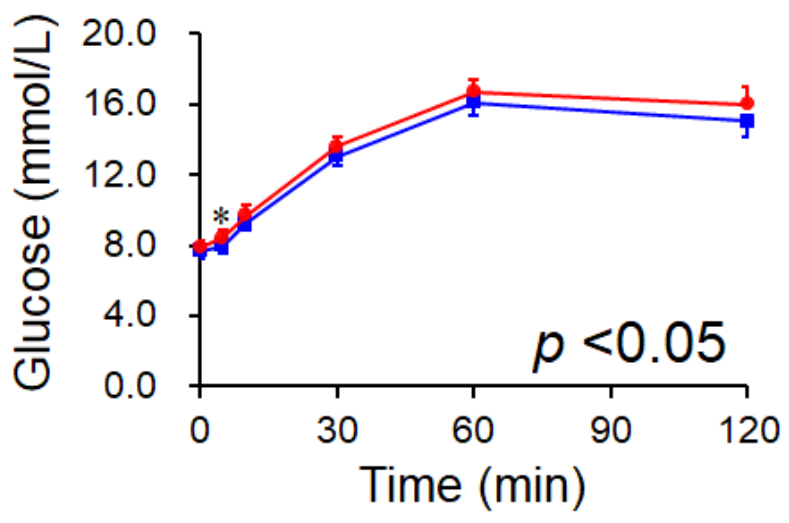

C

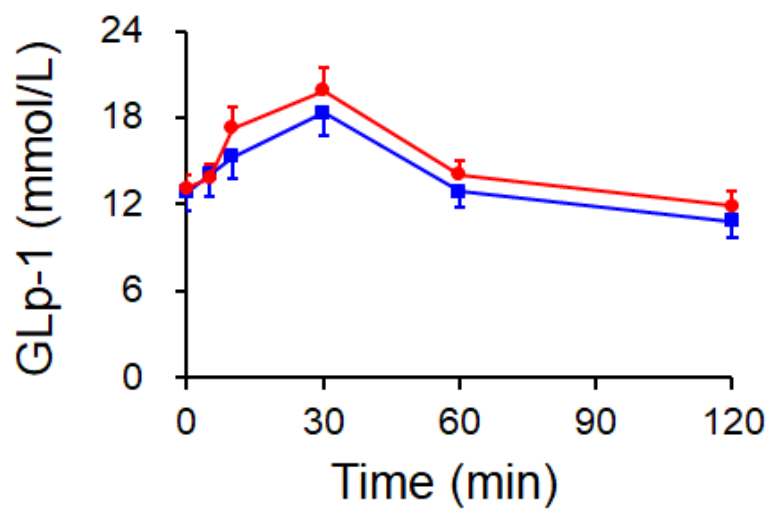

$\rightarrow$ Cold b

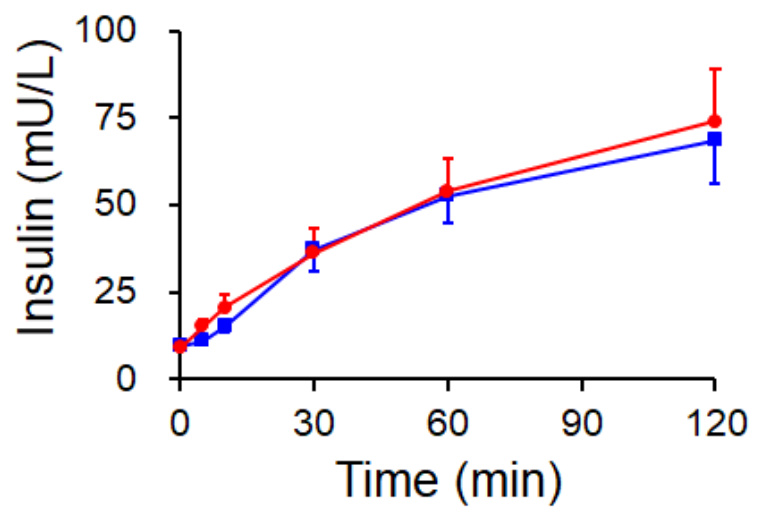

d

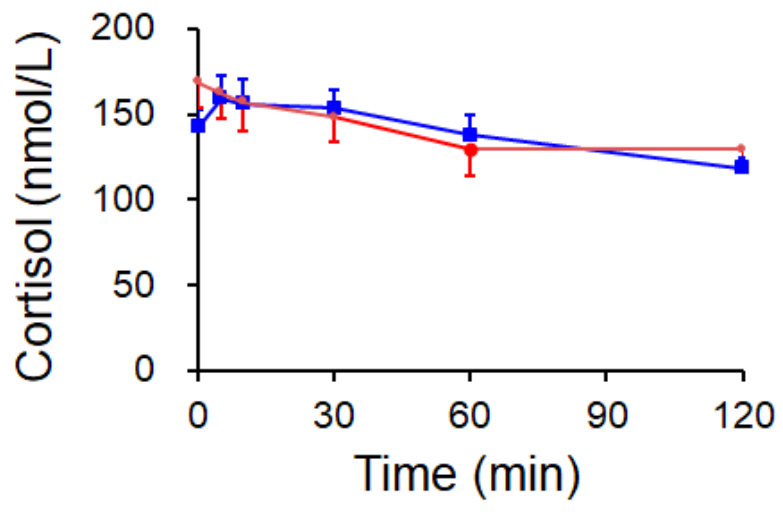

Figure 2

The blood glucose and glucose responsive hormone levels in cold and hot OGTTs in patients with T2DM. (a) blood glucose, (b) insulin, (c) GLP-1, and (d) cortisol levels in OGTTs in patients with newly diagnosed treatment naïve T2DM ( $n=22)$. Data were analyzed with ANOVA for repeated measurements, and all ' $p$ ' values are from the ANOVA. If there was statistical significance between the two temperatures $(p<0.05)$, this was followed with a Bonferroni test for specific time points. Blue line=cold OGTT; red line=hot OGTT; *, $p<0.05$ in Bonferroni test. OGTT, oral glucose tolerance test; GLP-1, Glucagon-like peptide-1. 
a

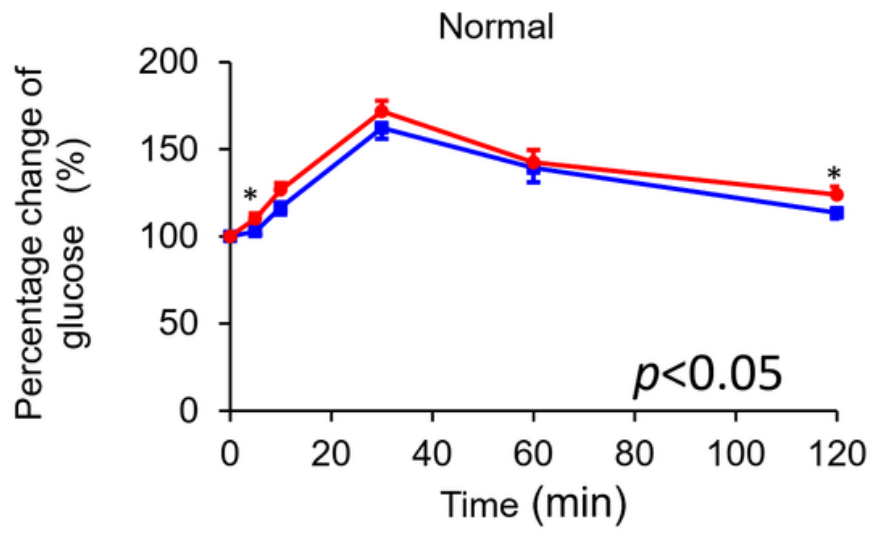

C

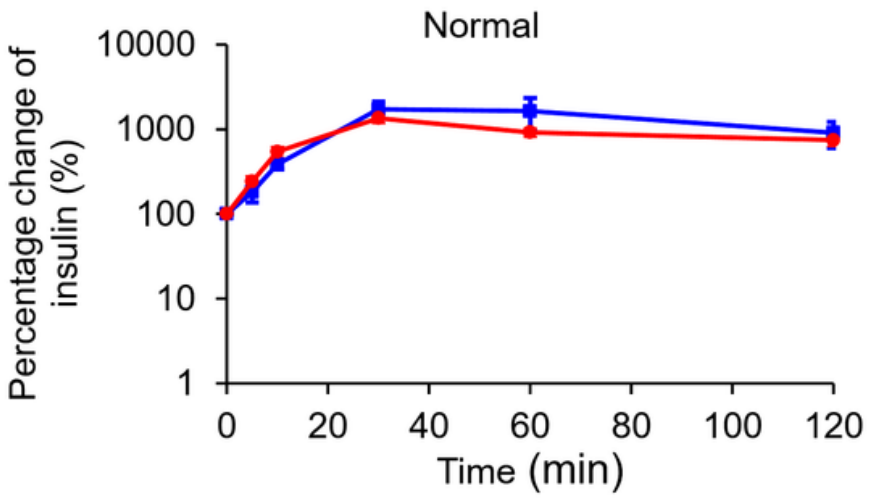

e

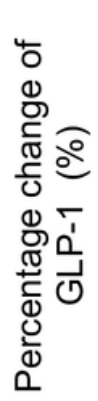

b

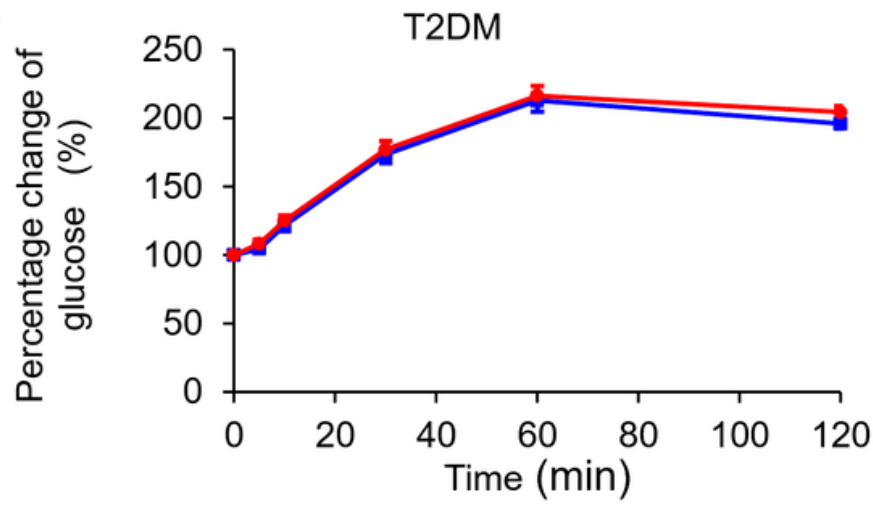

d

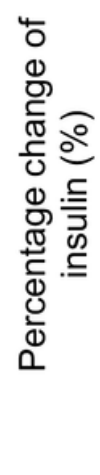

f

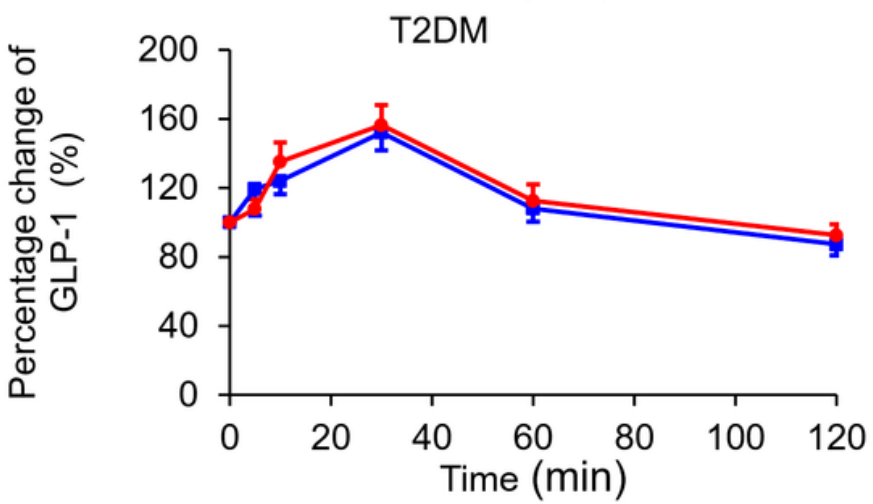

\section{Figure 3}

Percentage change of blood glucose and glucose responsive hormones in cold and hot OGTTs.

Percentage change from the baseline of OGTT were also calculated as follow: values at each time point / values at baseline $\times 100 \%)$. The percentage change of blood glucose ( $a$ and b), insulin (c and d), and GLP-1 (e and f) with OGTTs in normal $(n=19)$ and T2DM $(n=22)$ groups. Data were analyzed with ANOVA for repeated measurements. If there was statistical significance between the two temperatures $(p<0.05$ ANOVA), this was followed with a Bonferroni test for specific time points. Blue line=cold OGTT; red line=hot OGTT; * , $<0.05$ in Bonferroni test. OGTT, oral glucose tolerance test; GLP-1, Glucagon-like peptide-1; T2DM, type 2 diabetes mellitus. 